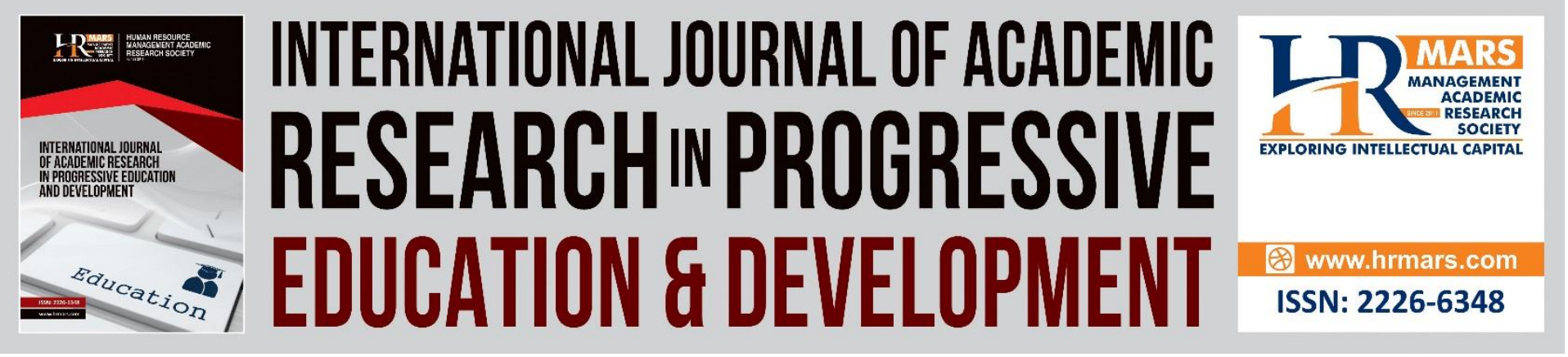

\title{
The Level of Critical Thinking Skills among New Graduate Nurses Through Practical Learning and Theoretical Learning
}

Tamilvani Narayanan \& Muhammad Zuhair Zainal

To Link this Article: http://dx.doi.org/10.6007/IJARPED/v11-i1/12021

DOI:10.6007/IJARPED/v11-i1/12021

Received: 07 November 2021, Revised: 14 December 2021, Accepted: 30 December 2021

Published Online: 24 January 2022

In-Text Citation: (Narayanan \& Zainal, 2022)

To Cite this Article: Narayanan, T., \& Zainal, M. Z. (2022). The Level of Critical Thinking Skills among New Graduate Nurses Through Practical Learning and Theoretical Learning. International Journal of Academic Research in Progressive Education and Development, 11(1), 413-427.

Copyright: (C) 2022 The Author(s)

Published by Human Resource Management Academic Research Society (www.hrmars.com)

This article is published under the Creative Commons Attribution (CC BY 4.0) license. Anyone may reproduce, distribute, translate and create derivative works of this article (for both commercial and non-commercial purposes), subject to full attribution to the original publication and authors. The full terms of this license may be seen

at: http://creativecommons.org/licences/by/4.0/legalcode

Vol. 11(1) 2022, Pg. 413 - 427

Full Terms \& Conditions of access and use can be found at http://hrmars.com/index.php/pages/detail/publication-ethics 


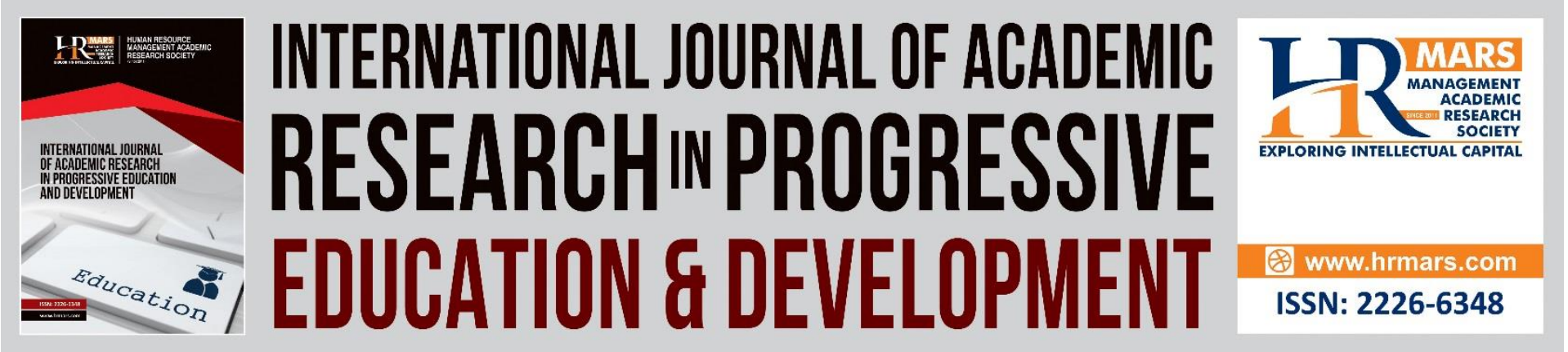

\title{
The Level of Critical Thinking Skills among New Graduate Nurses Through Practical Learning and Theoretical Learning
}

\author{
Tamilvani Narayanan \& Muhammad Zuhair Zainal \\ School of Educational Studies, Universiti Sains Malaysia \\ Corresponding author: zuhair@usm.my
}

\begin{abstract}
This quantitative research was conducted to examine the relationship between the level of critical thinking skills with practical learning and theoretical learning among new nurses serving. Quantitative data collection was done using the method of questionnaires. Results obtained using the ANOVA method prove that gender factors show significant data compared to age and marital status factors where the results for gender factors are $[F(1,132)=3.795$, $p=0.054$, partial eta squared $=.028]$ with alpha value is $(\alpha \leq 0.05)$ while for age factor is $[F$ $(1,132)=0.428, p>0.05$, partial eta squared $=.003]$ and marital status factor is $[F(1,132)=$ $0.007, p=0.933$, partial and squared $=.000$ ]. Further from the results obtained, it is shown that gender factors play an important role in the relationship of critical thinking skill levels. The implication from the findings of this study is to take into account gender factors by linking age factors and marital status in creating a balanced level of critical thinking.
\end{abstract}

Keywords: Critical Thinking Skills, Practical Learning, Theoretical Learning, New Graduate Nurse.

\section{Introduction}

Numerous writing state that critical thinking skills (CTS) can be defined as the thinking skills which refers to the ability to analyse information objectively and make a reasoned judgement. It involves the evaluation of sources such as data, facts, observable phenomenon and research findings. Good critical thinkers can draw reasonable conclusions from a set of information and discriminate between useful and less useful details to solve a problem or make a decision. Most writers paraphrased critical thinking as an activity includes problem solving, decision making, logical thinking, logical reasoning and creative thinking (Nickerson \& Argyres, 2018). Hussin et. al (2019) mentioned that there are two types of thinking skills; the creative and critical thinking skills. Way to enhance the CTS is by practical learning (PL) approach and theoretical learning (TL) approach which is being widely used in nursing educational institutions. Learning theories are the main guide for educational systems planning in the classroom and clinical training in nursing. By knowing the general principles in $\mathrm{PL}$ and $\mathrm{TL}$ all the new graduate nurse (NGN) can use their knowledge more effectively according to various learning situations which sharpen the CTS. PL is to put knowledge and 
skills into practice to motivate the new graduate nurses to think critically and hands-on learning strategies to help them meet their responsibilities and establish a life-long knowledge seeking habit which is self-directed learning.

$\mathrm{PL}$ and TL being major component in creating CTS in nursing field. Through PL and TL enables the NGNs cope with the fast-changing world where new knowledge is being produced while old knowledge is being reorganized and redefined. In nursing education, the major goal is the development and promotion of critical thinking nurses. While prospective employers seek qualities and skills which include the ability to think critically in order to make sound clinical judgments, nurse educators faced with the challenges of preparing new graduate nurses who must be adept at coping with the growing body of nursing knowledge, the rapid advances in science and technology and the economic constraints that continue to result from massive health care changes (Erikson \& Erikson, 2019). It is therefore a need to promote CTS among NGNs and create qualified nurses. Base on this, the following study will identify the level of CTS abilities of NGNs through PL curricular and TL curricular approaches.

\section{Literature Review}

a. Practical Learning and Theoretical Learning in Nursing Education

Various studies have done on PL and TL that develop the CTS among NGNs'. PL and TL are the both important learning process in nursing. Through this learning process the NGNs' will develop CTS which will make to critically solve the problems, make sound decision, analyze, reasons and evaluates. Tomaszewski (2021) explained CTS is a skill that gives better understanding of the connection in between idea and facts. It is the ability of thinking in an organized and rational manner. In nursing, Amy (2017) categorized CTS into divergent thinking which is the ability to weigh the importance of information gathered in order to explore alternatives and draw conclusions from the relevant data collected. Through PL and $T L$, the NGNs will get more information where they are able to experience and able to handle on their own. PL and TL allow NGNs' able to reason and it is another thinking skill that is important in that the nurses are able to discriminate between facts and non-facts so that decisions are made in a systematic, logical manner to solve problems and give good nursing care to patients. PL and TL will enable NGNs to clarify similarities and differences from relevant information will also help them to focus on the situation at hand. PL and TL give reflection for nurses to take time to think and compare different situation with similar solutions. This reflection in turn helps to develop CTS among NGNs' and to give them options and alternatives when caring for different patients. However, this reflection cannot take place in an emergency situation since the NGNs' needs to follow standard protocols in such situations. Though the nurse may know "the what" of thinking but from the nursing process, they also have to know "the how" of thinking skills required for a specific situation (Amy, 2017). The study also found that nursing educators and clinical instructors knew how to respond to the PL and TL curricular in developing CTS among NGNs'. Globally, CTS is an important and essential in every industry and every career and from entry to top executive level. CTS allow the employees to work both independently and with high problem solving skills (Indeed Editorial Team, 2021).

In a previous research on Critical Thinking: The Development of an Essential Skill for Nursing Students by Papathanasiou et al (2014), NGNs' apply CTS to develop attitudes and 
characteristics independence of thought, fairness, insight into the personal and public level, humble intellect and postpone the crisis, spiritual courage, integrity, perseverance, selfconfidence, research interest considerations not only behind the feelings and emotions but also behind the thoughts and curiosity through effective PL and TL. CTS through well motivated reasoning leads to reliable conclusions. Using CTS, NGNs' develop both the inductive and the deductive reasoning. The NGNs' gaining more experience of mental process and improvement, does not hesitate to disagree and be troubled thereby acting as a role model to colleagues, inspiring them to develop CTS in solving problem, decision making, analyzing, reasoning and evaluating.

Murray (2018) explained learning strategies to be reviewed with the improvised technique to enhance the CTS. Experiential learning or practical learning being a stepping stone to prepare the nurses to practice better in the clinical setting and enables them to solve problem and make sound decision. Practical learning allows the nursing educators to strategize and maximize the teaching and learning more meaningful to develop the CTS among nurses. Practical learning enhances the critical thinking through self-directed and transformational learning. It is a way of augmenting other learning method. Other than that nursing education through theoretical learning do give an impact to the development of CTS among nurses. The innovation in technology and new latest technique in education do give rise to the increase CTS. Computer assisted learning, distance learning through online using computers allow the nursing to access, analyze and manipulate information with increased CTS. This allows the nurses find information and reasoning it, responds to the situation and solve the problems.

Mahmoud (2014), identifying and clearing the loop hole of knowledge and practice in nursing is important. Educators and clinical instructors to instill adequate knowledge and practical to promote theory-practice integration to develop CTS which in turn optimize high quality patient care. To develop the CTS among the NGNs' need collaboration in theoretical and practical learning. The biggest challenge faced by the nursing educators and clinical instructors is to find ways to merge theory and practice in nursing education and patient care. This study strongly suggesting to achieve the optimize CTS among the nurse, educators and nurses need to spend time in teaching and learning clinical practice, update their clinical skills and re-experiencing the realities of practice. Theoretical knowledge with practical learning will reduce the anxiety in students and help them work effectively. Nursing education curriculum should cater facilities for students to acquire knowledge and skills. Thus, supply of proper simulation wards, practical labs and other needed resources is important.

\section{b. Critical Thinking Skills in Nursing Education}

CTS is major component in education field and it somehow differs between the NGNs' and seniors in that field. Thus, study was conducted in Kashan University of Medical Sciences during 2012 with 150 NGNs' and senior nursing staffs. CTS is critical to turn nursing education into professionalization. It is a process of purpose, interactive reasoning and judgment on nursing problems and the outcomes. This study concludes the CTS among nursing students was low and not to the expectation. Both group NGNs' and senior have the more or less equality of CTS. CTS among nurses is a continuous process and it should be continuously assessed over the time. The nursing curriculum should be revised and prepared for the 
implementation of innovative and active teaching and enhance the nurses' competency (Azizi-Fini et. al., 2015).

Education play major role in developing the CTS in every individual. Thus, nursing education bench marking the development of CTS in nurses. It is vital for the nursing educators to have in-depth understanding and dwell in the teaching and learning strategies to promote CTS in the student nurses and NGN's (Willers et al., 2021). The author furthered, the relationship among the educators and the NGN's, reflection practice and motivation to ask and clarify doubts will increase and promote the CTS among the NGN's.

Research conducted in Nursing Department of Technological Educational Institute of Thessaly, Greece and found CTS as a mental process that skillfully perception, analysis, synthesis and evaluating the collected information through observation, experience and communication that leads to a sound decision (Papathanasiou et al., 2014). CTS enable nurses to find specific solutions to specific problems with a positive effect and professional outcomes. The nursing education should adopt attitudes and curriculum that promotes CTS which mobilize the skills of solving problems, making clinical judgment, reasoning and evaluation.

Based on research done in the clinical setting, CTS is an essential element to provide excellent nursing care in the health care setting and must be encouraged among the healthcare workers. There must be a continuous effort in developing and implementing CTS in NGN's with proper measures that demonstrate their level and achievement of CTS. NGN's to improve their competencies in nursing career must obtain CTS as a fundamental component. Thus, the continuous research and future studies in CTS development is vital (Falcó-Pegueroles et al., 2020).

Study and literature review conducted on CTS among nursing students in Asian and Non-Asian countries. The CTS among Asian and Non-Asian were reviewed and compared. The comparative study of CTS among Asian and Non-Asian nursing students such as Iran, China, Japan and Hong Kong reflected low and Non-Asian Nursing students CTS tend to score high (Salsali et al., 2013). The reason why Asian nursing students CTS low and Non-Asian nursing students high identified as could due to environmental, educational methods and cultural differences. Concludes Asian countries nursing curriculum should be revised to shift the traditional thinking to $\mathrm{CT}$ among nursing students.

Zanariah and Norzaini (2012), studied CTS among nurses at College of Nursing Murni at Negeri Sembilan to measure the relationship and contribution of thinking style to learning style as well as the impact on the student's achievement. 157 samples randomly chose and quantitative study conducted. The study reveals the students CTS and the academic achievements among the nursing students depends on various issues such as interest of the students towards studies, self-esteem and environmental issues. Quality delivery of subject content which will enhance the thinking quality and CTS. The mixing of collaborative learning style and competitive learning style needed to develop the CTS among nursing students. 
A case study design used with a purposive sampling of six participants selected from a group of fourteen trained nurses from local medical college. The study findings contribute to create awareness among the educators, nursing administrators and senior clinical staff on the need to focus early development of CTS to the trainee nurses and NGNs' to make sound clinical judgment and problem solving in nursing practice. Teaching and learning should be a continuous process to improve CTS which will enhance the nursing practice (Mooi, 2015).

\section{Methodology}

Ethical Consideration: Written permission obtained from the particular health care organization after explaining the purpose, format and the potential benefits from the study. The study purpose and contain explained to the Director of Nursing of the health care organization and followed by the nurses' concern. Written consent and permission received to conduct research in the particular health care settings. Participating health care organizations and the participant's identity kept confidentially and protected.

Study design, population and sampling method: The research conducted in quantitative study design which comprises total number of respondents of 132 new graduate nurses from different private hospitals in Penang that were included in this research. The new graduate critical thinking skills measured through adapted questionnaires Critical Thinking Skill Test (CCTST) and California Critical Thinking Disposition Inventory (CCTDI). Descriptive analysis of questionnaires followed by the assumptions for statistical tests used for data analysis.

\section{Results}

The total numbers of respondents were 132 new graduate nurses from different private hospitals in Penang that were included in this research. The independent variables practical learning and theoretical learning was embedded in the curriculum of all the new graduate nurses. The dependent variable that is critical thinking skills is measured using the adapted questionnaires CCTST and CCTDI. For validating the suitability of the questionnaire, Curriculum study experts from University Science Malaysia had evaluated and verified the questionnaires.

\section{a. Descriptive Analysis}

A descriptive analysis is based on data collected from the whole population and is demonstrated using basic statistics such as frequency and percentage (Chua, 2006). Thus, research data on the age of new graduate nurses having completed either diploma or degree course has been tabulated using frequency and percentage.

\section{Sample Distribution by Age}

The samples needed in this research are new graduate nurses from both nursing diploma and degree course. The sample size obtained was 132 new graduate nurses from the in-patient and out-patient unit within Penang. Accordingly, the graduate nurses that were from 20-25 years old were 76 students (57.6\%) and nurses from $26-30$ years old were 56 students $(42.4 \%)$. The frequency distribution and percentage of student's age is shown in Table 1 
Table 1. Frequency and percentage of new graduate nurses according to age sample distribution by gender.

\begin{tabular}{lll}
\hline Age & Frequency & Percentage \\
\hline $20-25$ & 76 & $57.6 \%$ \\
$26-30$ & 56 & $42.4 \%$ \\
& & \\
Total & 132 & \\
\hline
\end{tabular}

The descriptive analysis has found that 82 comprised new graduate nurses at $62.1 \%$ and 50 comprised of new graduate nurses at $37.9 \%$. The frequency and percentage distribution are shown in Table 2.

Table 2. Frequency and percentage of new graduate nurses according to gender sample distribution by marital status.

\begin{tabular}{lll}
\hline Gender & Frequency & Percentage \\
\hline Female & 82 & $62.1 \%$ \\
Male & 50 & $37.9 \%$ \\
Total & 132 & \\
\hline
\end{tabular}

The descriptive analysis has found that 84 comprised of new graduate nurses who were married at $63.6 \%$ and 48 comprised of new graduate nurses who were still single at 36.3\%. The frequency and percentage of distribution is shown in Table 3.

Table 3. Frequency and percentage of new graduate nurses according to marital status.

\begin{tabular}{lll}
\hline Gender & Frequency & Percentage \\
\hline Married & 84 & $63.6 \%$ \\
Single & 48 & $36.3 \%$ \\
Total & 132 &
\end{tabular}

The descriptive statistics tables both (Table 4 and Table 5) show the mean and standard deviation scores for critical thinking skills and its constructs (problem solving, decision making and reasoning) among new graduate nurses in private hospitals at Penang. The mean scores for all the three constructs are moderate and the differences in mean are minimal. The standard deviation scores for reasoning were the highest followed by problem solving and subsequently decision making.

Table 4. Mean score analysis (Mean), standard deviation (SD) and critical thinking skills constructs among new graduate nurses.

\begin{tabular}{llll}
\hline $\begin{array}{l}\text { Critical Thinking } \\
\text { Skills }\end{array}$ & Mean Score & $\begin{array}{l}\text { Interpretation } \\
\text { Mean }\end{array}$ & of \\
\hline 1. Problem Solving & 25.43 & Moderate & 4.20 \\
2. Decision Making & 19.28 & Moderate & 3.90 \\
3. Reasoning & 27.30 & Moderate & 4.85 \\
\hline
\end{tabular}


Table 5: Descriptive statistics of survey scores among new graduate nurses.

\begin{tabular}{lll}
\hline Survey & Mean & Standard Deviation \\
\hline Critical Thinking Skills & 24.00 & 3.38 \\
\hline
\end{tabular}

b. Assumptions for ANOVA

The dependent variable should be either in interval or ratio; that is continuous in nature. Typically, scores that are continuous in this research is the Critical Thinking Skills scores that are at the range of 10 to 44 . Secondly, the independent variables consist of two or more independent and categorical groups (e.g. age, gender and ethnicity). In this research, age, gender and marital status of the new graduate nurses is considered as categorical independent variables that have been investigated in this study. The next assumption is that there is independence in observations between the independent variables; that is the group of people in each independent variable is different and separate from each other. Importantly, the dependent variable should have a normal distribution for each category of independent variable. This is tested using the Kolmogorov Smirnov test of normality as the sample is more than 30 respondents (Gay et al., 2012). Also, homogeneity of variances should be assumed in a One-way ANOVA and this is measured using the Levene's Test for Homogeneity of variances.

An essential assumption to meet for a one-way ANOVA is the normality of distribution (Hair, et al., 2018). This distribution of normality is calculated to determine how the data is distributed throughout the sample from the population indicated by distribution form. In the event that the data deviation from the normal distribution is sufficiently high, the subsequent inferential statistical tests carried out are deemed invalid because of the breach of this presumption (Hair et al., 2018). Skewness and kurtosis can be used to demonstrate the distribution's shape and normality. Skewness refers to the orientation and equilibrium of the bell curve (e.g. positive or negatively skewed) while kurtosis refers to the distribution's height. The values for asymmetry and kurtosis between -3 and +3 are considered acceptable in order to prove normal univariate distribution (George \& Mallery, 2010). Table 6 below shows the skewness and kurtosis for the dependent variable critical thinking skills. Since the values are between +3 to -3 , critical thinking skills can be considered to have a normal distribution.

Table 6: Skewness and Kurtosis.

\begin{tabular}{lll}
\hline Variable & Skewness & Kurtosis \\
\hline Critical Thinking Skills & .638 & 2.204 \\
\hline
\end{tabular}

Another method of checking if the data is normality of distributed is through the Kolmogorov Smirnov normality test and the $p$ value should be more than the alpha value ( $p>$ $0.05)$. In this research, the $p$-value from the normality testing for age is 0.068 ( $p>0.05)$ for 20 25 years old and $p$-value is 0.200 for $26-30$ years old that depicts a normal distribution for Critical Thinking Skills among the new graduate nurses. Table 7, Table 8 and Table 9 indicates 
the $p$-value from the Kolmogorov-Smirnov test for age, gender and marital status towards critical thinking skills and even gender and marital status indicates a normal distribution as $\mathrm{p}>0.05$.

Table 7. Test of Normality for age.

\begin{tabular}{lll}
\hline Variable & $20-25$ & $26-30$ \\
\hline Age & 0.068 & 0.200 \\
\hline
\end{tabular}

Table 8. Test of Normality for gender.

\begin{tabular}{lll}
\hline Variable & Female & Male \\
\hline Gender & .200 & 0.162 \\
\hline
\end{tabular}

Table 9. Test of Normality for marital status

\begin{tabular}{lll}
\hline Variable & Single & Married \\
\hline Marital Status & .200 & 0.060 \\
\hline
\end{tabular}

The homogeneity of variances indicates whether two populations have the same distribution and an equality of variances within the distribution. Typically, the Levene's Test is used to indicate the weather homogeneity of variances is assumed within the population and a $p$ value of $>0.05(\alpha=0.05)$ indicates there is an equality of variances assumed within the population. As such, Table 1.10 shows the $p$-value of the homogeneity of variances within the population. Based on the table, there is an equality of variances assumed within the population (age, $p=.182$; gender, $p=.256$; marital status, $p=.463$ ).

Table 10. Levene's test of homogeneity.

\begin{tabular}{ll}
\hline Variable & Sig. \\
\hline Age & .182 \\
Gender & .256 \\
Marital Status & .463 \\
\hline
\end{tabular}

Based on the ANOVA analysis, the Table 11 depicts the results from the one-way ANOVA analysis for Research Question 2: Does age, gender and marital status contribute to the level of critical thinking skills among new graduate nurses through practical learning and theoretical learning?

Table 11. Test of between subjects effects.

\begin{tabular}{lllll} 
Factors & $\mathrm{F}$ & $\mathrm{df}$ & Sig. & Partial Eta \\
\hline Age & 0.428 & 1 & 0.514 & 0.003 \\
Gender & 3.795 & 1 & 0.054 & 0.028 \\
Marital Status & 0.007 & 1 & 0.933 & 0.000 \\
\hline
\end{tabular}

The Table 11 proves that age has no significant difference towards the level of critical thinking skills $[F(1,132)=0.428, p>0.05$, partial eta squared $=.003]$. Importantly, it is good to note that gender has made a significant difference towards the level of critical thinking 
skills $[F(1,132)=3.795, p=0.054$, partial eta squared $=.028]$ at alpha level $(\alpha \leq 0.05)$. Marital Status has no significant difference towards the level of critical thinking skills $[F(1,132)=$ $0.007, p=0.933$, partial eta squared $=.000$ ]. From the results above, $2.8 \%$ of variance in the level of critical thinking skills can be explained by gender that indicates gender has a minimal impact on the level of critical thinking skills.

\section{c. Assumptions for MANOVA}

For a MANOVA analysis, the multivariate normality is a crucial assumption to meet to indicate the normality of distribution within the population (Hair et al., 2018). Skewness and kurtosis can be used to indicate the normality of distribution in the population. In this research, the skewness and kurtosis for the multivariate under Critical Thinking Skills can be depicted in the Table 1.12 below. The table below shows a skewness and kurtosis for problem solving, $p=0.187$, decision making, $p=0.488$ and reasoning, $p=0.831$. Based on these values, there is an indication of normality as the values of skewness and kurtosis fall between -2 to +2 (George \& Mallery, 2010).

Table 12. Skewness and Kurtosis.

\begin{tabular}{lll}
\hline Variable & Skewness & Kurtosis \\
\hline Problem Solving & 0.187 & .723 \\
Decision Making & 0.488 & .811 \\
Reasoning & 0.831 & 1.544 \\
\hline
\end{tabular}

The Box's M Test of Covariance Matrices Equality has been used to test if there is homogeneity of the variance assumed in the population within the sample. The null hypothesis is evaluated to see whether the dependent variables' covariance matrices observed are equal across groups (Hair et al., 2018). In this analysis the Box-M equality of covariance is shown in Table 13 below.

Table 13. Box's test of equality of covariance matrices

\begin{tabular}{ll}
\hline Criteria & Value \\
\hline Box's M & 49.206 \\
F & 1.010 \\
df1 & 42 \\
df2 & 2246.540 \\
Sig. & .454 \\
\hline
\end{tabular}

The Box $M$ results indicate that there is no significant difference in the hypothesis, $[\mathrm{F}$ $(42,2246.540)=49.206, p=0.454, p>0.05]$ which fulfills the homogeneity of variancecovariance matrices assumption. Hence, the $p$-value of 0.454 proves that the null hypothesis is accepted and there is an equality of variance-covariance assumed within the population.

Table 14. Levene's test of equality of error variances.

\begin{tabular}{lllll}
\hline $\begin{array}{l}\text { Dependent } \\
\text { Variables }\end{array}$ & $\mathbf{F}$ & $\mathbf{d f 1}$ & $\mathbf{d f 2}$ & Sig. \\
\hline $\begin{array}{l}\text { Problem } \\
\text { Solving }\end{array}$ & 1.344 & 1 & 130 & 0.248
\end{tabular}




\begin{tabular}{lcccc}
$\begin{array}{l}\text { Decision } \\
\text { Making }\end{array}$ & 0.129 & 1 & 130 & 0.720 \\
Reasoning & 7.384 & 1 & 130 & 0.007 \\
\hline
\end{tabular}

Based on the Table 14, the levene 's equality of error variances test showed that the variances for each category of the dependent variables were not the same. The results showed that two of the dependent variables, problem solving and decision making achieved a non-significant result for the Levene's Test, (problem solving, $p=0.248$ and decision making, $p=0.720$ ) and $\alpha=0.05$ level. Since $p>0.005$ for problem solving and decision making, an equality of homogeneity is assumed within the population. In terms of reasoning, $p=0.007$, $(p<0.005)$ that depicts an inequality of error variances whereby Pillai's Trace should be taken with this assumption (Hair et al., 2018).

Table 15. Multivariate tests.

\begin{tabular}{|c|c|c|c|c|c|c|}
\hline Effect & Intercept & Value & $F$ & $\begin{array}{l}\text { Hypothesis } \\
\text { df }\end{array}$ & Error df & Sig. \\
\hline Age & $\begin{array}{l}\text { Pillai's } \\
\text { Trace } \\
\text { Wilk's } \\
\text { Lamda } \\
\text { Hotelling's } \\
\text { Trace } \\
\text { Roy's } \\
\text { Largest } \\
\text { Root }\end{array}$ & $\begin{array}{l}0.008 \\
0.992 \\
0.008 \\
0.008\end{array}$ & 0.318 & 3.00 & 122.00 & 0.812 \\
\hline Gender & $\begin{array}{l}\text { Pillai's } \\
\text { Trace } \\
\text { Wilk's } \\
\text { Lamda } \\
\text { Hotelling's } \\
\text { Trace } \\
\text { Roy's } \\
\text { Largest } \\
\text { Root }\end{array}$ & $\begin{array}{l}0.026 \\
0.974 \\
0.027 \\
0.027\end{array}$ & 1.097 & 3.00 & 122.00 & 0.353 \\
\hline Marital Status & $\begin{array}{l}\text { Pillai's } \\
\text { Trace } \\
\text { Wilk's } \\
\text { Lamda } \\
\text { Hotelling's } \\
\text { Trace } \\
\text { Roy's } \\
\text { Largest } \\
\text { Root }\end{array}$ & $\begin{array}{l}0.038 \\
0.962 \\
0.040 \\
0.040\end{array}$ & 1.622 & 3.00 & 122.00 & 0.188 \\
\hline
\end{tabular}




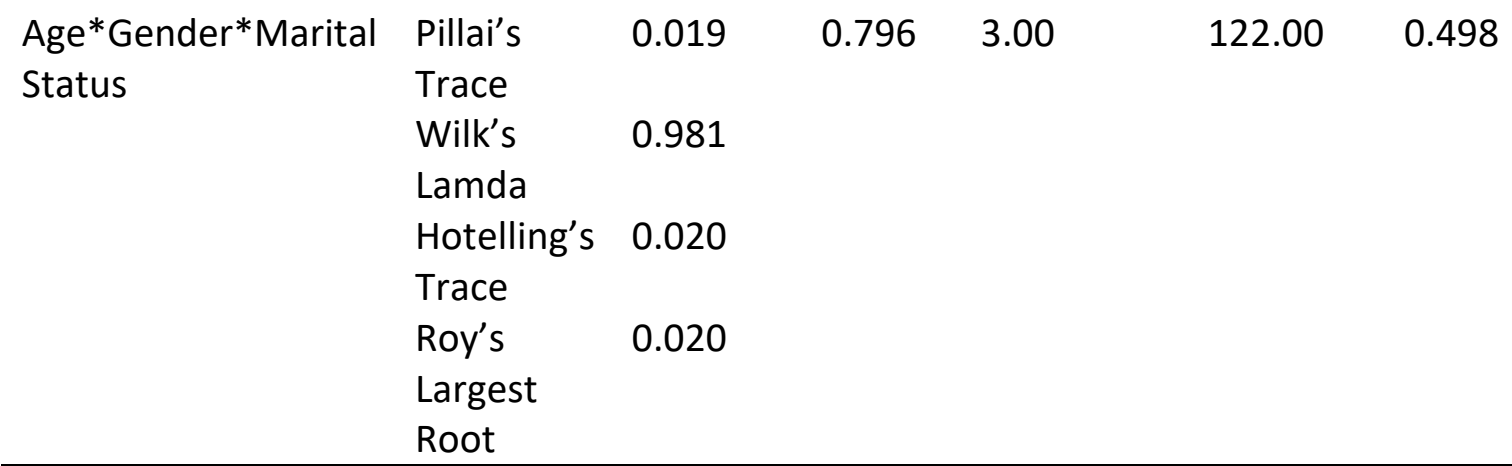

The results of the Pillai trace test in Table 1.14 indicate that, overall, age [F (3.00, $122.00)=0.318, p>.05]$ gender $[F(3.00,122.00)=1.097, p>.05]$ and marital status $[F(3.00$, $122.00)=1.622, p>.05]$ had no significant effect towards the dependent variables, problem solving, decision making and reasoning. There was no interaction effect between the three independent variables and the three dependent variables based on Age* Gender*Marital Status in this study $[F(3.00,122.00)=0.796, p>.05]$. Based on the results of this study, the null hypothesis was failed to be rejected and subsequently reported that overall, age, gender and marital status were not important factors in the three aspects of critical thinking skills.

Table 16. Tests of between-subjects effect analysis

\begin{tabular}{|c|c|c|c|c|}
\hline Cause & $\begin{array}{l}\text { Dependent } \\
\text { Variable }\end{array}$ & $\mathrm{F}$ & $d f$ & Sig. \\
\hline \multirow[t]{4}{*}{ Age } & Problem & 0.803 & 1 & 0.372 \\
\hline & Solving & & & \\
\hline & Decision & 0.406 & 1 & 0.525 \\
\hline & Making & & & \\
\hline \multirow[t]{5}{*}{ Gender } & Reasoning & 0.008 & 1 & 0.930 \\
\hline & Problem & 2.271 & 1 & 0.134 \\
\hline & Solving & 1.660 & 1 & 0.200 \\
\hline & Decision & 0.003 & 1 & 0.957 \\
\hline & Making & & & \\
\hline \multirow[t]{8}{*}{ Marital Status } & Reasoning & & & \\
\hline & & 0.011 & 1 & 0.916 \\
\hline & & 0.467 & 1 & 0.496 \\
\hline & Problem & 1.882 & 1 & 0.173 \\
\hline & Solving & & & \\
\hline & Decision & & & \\
\hline & Making & & & \\
\hline & Reasoning & & & \\
\hline Age*Gender*Marital & Problem & 2.286 & 1 & 0.133 \\
\hline \multirow[t]{3}{*}{ Status } & Solving & 0.273 & 1 & 0.602 \\
\hline & Decision & 0.338 & 1 & 0.562 \\
\hline & Making & & & \\
\hline
\end{tabular}


Reasoning

Based on Table 15, the results of the tests of between-subjects effect showed that there was no significant main effect with age towards all three dependent variables, Problem Solving $[F(1,132)=0.803, p>.05]$, Decision Making $[F(1,132)=0.406, p>.05]$, Reasoning $[F$ $(1,132)=0.008, p>.05]$. Similarly, the results of the tests of between-subjects effect showed that there was no significant main effect of gender towards all three dependent variables, Problem Solving $[F(1,132)=2.271, p>.05]$, Decision Making $[F(1,132)=1.660, p>.05]$, Reasoning $[F(1,132)=0.003, p<.05]$. Also, there is no main effect of marital status towards all three dependent variables, Problem Solving $[F(1,132)=0.011, p>.05]$, Decision Making $[F$ $(1,132)=0.467, p>.05]$, Reasoning $[F(1,132)=1.882, p>.05]$. There is also no main interaction effect between age, gender and marital status towards Problem Solving $[F(1,132)=2.286$, $p>.05]$, Decision Making $[F(1,132)=0.273, p>.05]$, Reasoning $[F(1,132)=0.338, p>.05]$.

\section{Discussion and Conclusion}

The independent variables practical learning and theoretical learning was embedded in the curriculum of all the new graduate nurses. The dependent variable that is critical thinking skills is measured using the adapted questionnaires CCTST and CCTDI. The quantitative data gives the researcher a path to investigate more on the insights of the study and also precise on describing the descriptive data.

A deeper understanding of the level of Critical Thinking Skills among New Graduate Nurses in problem solving, decision making, and reasoning will definitely contribute to a better implementation of these two different types of curricular in nursing field which will also help to guide the nursing educators to instruct their New Graduate Nurses better. The study will be significant because it provides empirical evidence supporting the level of Critical Thinking Skills among New Graduate Nurses through Practical Learning and Theoretical Learning. The study will create awareness about the level of Critical Thinking Skills among New Graduate Nurses through Practical Learning and Theoretical Learning in problem solving, decision making, and reasoning in Nursing Care. Practical Learning and Theoretical Learning curricular is part of nursing education globally. In ancient days nursing education is only through experience and bedside care of patient's daily activities. Nurses were acted as "handmaidens" of doctors. The process of professionalism developed and Practical Learning curricular and Theoretical Learning curricular implemented to enhance the nurses Critical Thinking Skills and Nursing Care.

In addition, this study aimed to provide a comprehensive understanding on the level of Critical Thinking Skills among New Graduate Nurses through Practical Learning and Theoretical Learning. Therefore, the New Graduate Nurses and nursing educators will be able to customize teaching and learning based on the results of the findings in this study. In responsible positions nurses should be especially aware of the climate of thought that is implemented and actively create an environment that stimulates and encourages diversity of opinion and research ideas. The nurses will also be applied to investigate the views of people from different cultures, religions, social and economic levels, family structures and different ages. Managing nurses should encourage colleagues to scrutinize the data prior to draw conclusions and to avoid "group thinking" which tends to vary without thinking of the will of 
the group. Critical thinking is an essential process for the safe, efficient and skilful nursing practice. The nursing education programs should adopt attitudes that promote critical thinking and mobilize the skills of critical reasoning.

\section{Recommendations for Future Research}

This research might encourage future researcher to do more investigation about the Critical Thinking Skills based on Practical Learning and Theoretical Learning in a more empirical based research by incorporating an intervention based programme for the nurses to undertake consistently for certain weeks to enable the nurses to acquire the skills needed to nurture the Critical Thinking Skills which can be a catalyst through workshop-based interventions to promote the skill based on Practical Learning and Theoretical Learning.

The number of respondents also can be increased to further improve on the reliability of the data. Besides that, both government and private sector nurses can be given the intervention to collaborate as a cross case study can be conducted for more persist data collection. Besides that, a semi-structured interview also may useable for the development of future studies in the current literature of Critical Thinking Skills that is lacking in term of its prevalence among nurses in Malaysia.

\section{Corresponding Author}

Muhammad Zuhair Zainal

Senior Lecturer School of Educational Studies, Universiti Sains Malaysia 11800 Minden, Penang, Malaysia

Emel: zuhair@usm.my

\section{References}

Amy, J. B. (2017). Call for action: Nurses must play a critical role. American Academy on Policy. Nursing Outlook.

Azizi-Fini, I., Hajibagheri, A., \& Adib-Hajbaghery, M. (2015). Critical thinking skills in nursing students: a comparison between freshmen and senior students. Nursing and midwifery studies, 4(1).

Erikson, M. G., \& Erikson, M. (2019). Learning outcomes and critical thinking-good intentions in conflict. Studies in Higher Education, 44(12), 2293-2303.

Falcó-Pegueroles, A., Rodríguez-Martín, D., Ramos-Pozón, S., \& Zuriguel-Pérez, E. (2021). Critical thinking in nursing clinical practice, education and research: From attitudes to virtue. Nursing Philosophy, 22(1), e12332.

Gay, L. R., Mills, G. E., \& Airasian, P. W. (2012). Educational research: Competencies for analysis and application (10th ed.). Englewood Cliffs, NJ: Prentice Hall.

George, D., \& Mallery, M. (2010). SPSS for Windows step by step: A simple guide and reference, 17.0 update (10a ed.). Boston: Pearson.

Hair, J. P., Babin, B. J., Anderson, R. E., \& Black, W. C. (2018). Multivariate data analysis: Global edition (8th Edition). Kennesaw State University: Pearson Education.

Hussin, W. N. T. W., Harun, J., \& Shukor, N. A. (2019). Problem based learning to enhance students critical thinking skill via online tools. Asian Social Science, 15(1), 14-23.

Indeed Editorial Team. (2021). 10 essential critical thinking skills (and how to improve them). https://www.indeed.com/career-advice/career-development/critical-thinking-skills 
Mahmoud, M. H. (2014). Practical learning and theory practice gap as perceived by nursing students. Inter J Cur Res, 6(2), 5083-5093.

Murray, R. (2018). An overview of experiential learning in nursing education. Advances in Social Sciences Research Journal, 5(1).

Nickerson, J., \& Argyres, N. (2018). Strategizing before strategic decision making. Strategy Science, 3(4), 592-605.

Papathanasiou, I. V., Kleisiaris, C. F., Fradelos, E. C., Kakou, K., \& Kourkouta, L. (2014). Critical thinking: the development of an essential skill for nursing students. Acta Informatica Medica, 22(4), 283.

Salsali, M., Tajvidi, M., \& Ghiyasvandian, S. (2013). Critical thinking dispositions of nursing students in Asian and non-Asian countries: A literature review. Global Journal of Health Science, 5(6), 172.

Tomaszewski, M. (2021). Career expert at resumelab. https://resumelab.com/about/michaeltomaszewski

Willers, S., Jowsey, T., \& Chen, Y. (2021). How do nurses promote critical thinking in acute care? A scoping literature review. Nurse Education in Practice, 53. https://doi.org/10.1016/j.nepr.2021.103074

Mooi, Y. N. (2015). Critical Thinking Skills Among Trained Nurses On Patient Diabetic Care Management: A Case Study. PhD thesis, Universiti Sains Malaysia. 